\title{
Automatic irrigation system on sensing soil moisture content
}

\author{
Nagarajapandian $M^{1}$, Ram Prasanth $\mathbf{U}^{2}$, Selva Kumar $\mathbf{G}^{3}$, Tamil Selvan $\mathrm{S}^{4}$ \\ Assistant professor, Dept. of EIE, Sri Ramakrishna Engineering College, Coimbatore, Tamilnadu, India ${ }^{1}$ \\ UG Student, Dept. of EIE, Sri Ramakrishna Engineering College, Coimbatore, Tamilnadu, India ${ }^{2,3,4}$
}

\begin{abstract}
This project on "Automatic Irrigation System on Sensing Soil Moisture Content" is intended to create an automated irrigation mechanism which turns the pumping motor ON and OFF on detecting the dampness content of the earth. In the domain of farming, utilization of appropriate means of irrigation is significant. The benefit of employing these techniques is to decrease human interference and still make certain appropriate irrigation. This automated irrigation project brings into play an Arduino board ATmega328 micro-controller is programmed to collect the input signal of changeable dampness circumstances of the earth via dampness detecting system.
\end{abstract}

Keywords: Microcontroller, Irrigation, Soil Moisture Content, Automated Irrigation Mechanism.

\section{I.INTRODUCTION}

The continuous increasing demand of food requires the rapid improvement in food production technology. In a country like India, where the economy is mainly based on agriculture and the climatic conditions are isotropic, still we are not able to make full use of agricultural resources. The main reason is the lack of rains \& scarcity of land reservoir water. The continuous extraction of water from earth is reducing the water level due to which lot of land is coming slowly in the zones of un-irrigated land. Another very important reason of this is due to unplanned use of water due to which a significant amount of water goes to waste.

In modern drip irrigation systems, the most significant advantage is that water is supplied near the root zone of the plants drip by drip due to which a large quantity of water is saved. At the present era, the farmers have been using irrigation techniques in India through manual control in which farmers irrigate the land at the regular intervals. This process sometimes consumes more water or sometimes the water reaches late due to which crops

Get dried. Water deficiency can be detrimental to plants before visible wilting occurs. Slowed growth rate, lighter weight fruit follows slight water deficiency. This problem can be perfectly rectified if we use automatic micro controller based drip irrigation system in which the irrigation will take place only when there will be acute requirement of water.

\section{II.IRRIGATION}

Irrigation system uses valves to turn irrigation $\mathrm{ON}$ and OFF. These valves may be easily automated by using controllers and solenoids. Automating farm or nursery irrigation allows farmers to apply the right amount of water at the right time, regardless of the availability of labor to turn valves on and off. In addition, farmers using automation equipment are able to reduce runoff from over watering saturated soils, avoid irrigating at the wrong time of day, which will improve crop performance by ensuring adequate water and nutrients when needed. Automatic Drip Irrigation is a valuable tool for accurate soil moisture control in highly specialized greenhouse vegetable production and it is a simple, precise method for irrigation. It also helps in time saving, removal of human error in adjusting available soil moisture levels and to maximize their net profits.

Irrigation is the artificial application of water to the soil usually for assisting in growing crops. In crop production it is mainly used in dry areas and in periods of rainfall shortfalls, but also to protect plants against frost.

Types of Irrigation

\section{- Surface irrigation \\ Localized irrigation \\ Drip Irrigation \\ Sprinkler irrigation}

The conventional irrigation methodslike overhead sprinklers, flood type feeding systems usually wet the lower leaves and stem of the plants. The entire soil surfaceis saturated and often stays wet long after irrigation is completed. Such condition promotes infections by leaf mold fungi. On the contrary the drip or trickle irrigation is a type of modern irrigation technique that slowly applies small amounts of water to part of plant root zone. Water is supplied frequently, often daily to maintain favorable soil moisture conditionand prevent moisture stress in the plant with proper use of water resources.Drip irrigation saves water because only the plant's root zone receives moisture. Little water is lost to deep percolation if the proper amount is applied. Drip irrigation is popular because it can increase yields and decrease both water requirements and labor.

Drip irrigation requires about half of the water needed by sprinkler or surface irrigation. Lower operating pressures and flow rates result in reduced energy costs. A higher degree of water control is attainable.

Plants can be supplied with more precise amounts of water. Disease and insect damage is reduced because plant foliage stays dry. Operating cost is usually reduced. Federations may continue during the irrigation process because rows between plants remain dry. 


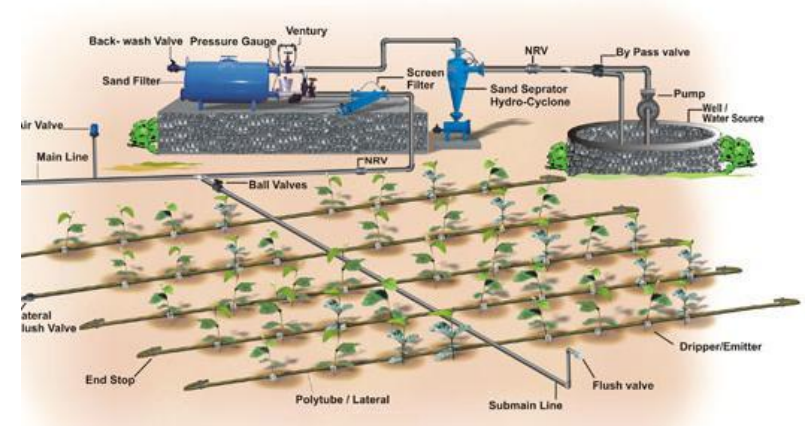

Fig. 1 Overview of Automated Irrigation System

The above fig 1 explains about important parameters to be measured for automation of irrigation system are soil moisture. The entire field is first divided into small sections such that each section should contain one moisture sensor. These sensors are buried in the ground at required depth. Once the soil has reached desired moisture level the sensors send a signal to the micro controller to turn on the relays, which control the motor.

In proposed system, automated irrigation mechanism which turns the pumping motor $\mathrm{ON}$ and OFF on detecting the dampness content of the earth. In the domain of farming, utilization of appropriate means of irrigation is significant. The benefit of employing these techniques is to decrease human interference. This automated irrigation project, the soil sensor senses the moisture content by giving input signal to an Arduino board which operates on ATmega328 micro-controller, is programmed to collect the input signal of changeable dampness circumstances of the earth via dampness detecting system.

\section{III.SOIL MOISTURE}

Soil moisture is an important component in the atmospheric water cycle, both on a small agricultural scale and in large-scale modelling of land/atmosphere interaction. Vegetation and crops always depend more on the moisture available at root level than on precipitation occurrence. Water budgeting for irrigation planning, as well as the actual scheduling of irrigation action, requires local soil moisture information. Knowledge of the degree of soil wetness helps to forecast the risk of flash floods, or the occurrence of fog.

Soil water content is an expression of the mass or volume of water in the soil, while the soil water potential is an expression of the soil water energy status. The relation between content and potential is not universal and depends on the characteristics of the local soil, such as soil density and soil texture.

The basic technique for measuring soil water content is the gravimetric method. Because this method is based on direct measurements, it is the standard with which all other methods are compared. Unfortunately, gravimetric sampling is destructive, rendering repeat measurements on the same soil sample impossible. Because of the difficulties of accurately measuring dry soil and water volumes, volumetric water contents are not usually determined directly.
The capacity of soil to retain water is a function of soil texture and structure. When removing a soil sample, the soil being evaluated is disturbed, so its water-holding capacity is altered. Indirect methods of measuring soil water are helpful as they allow information to be collected at the same location for many observations without disturbing the soil water system. Moreover, most indirect methods determine the volumetric soil water content without any need for soil density determination. The new soil moisture sensoruses Immersion Gold which protects the nickel from oxidation. Electrodes nickel immersion gold (ENIG) has several advantages over more conventional (and cheaper) surface plating such as

HASL (solder), including excellent surface planarity (particularly helpful for PCB's with large BGA packages), good oxidation resistance, and usability for untreated contact surfaces such as membrane switches and contact points.

A soil moisture sensor can read the amount of moisturepresent in the soil surrounding it. It's a low tech sensor, but ideal for monitoring an urban garden, or your pet plant's water level. This is a must have tool for a connected garden.

This sensor uses the two probes to pass current through the soil, and then it reads that resistance to get the moisture level. More water makes the soil conduct electricity more easily (less resistance), while dry soil conducts electricity poorly (more resistance).

\section{IV.BLOCK DIAGRAM AND WORKING}

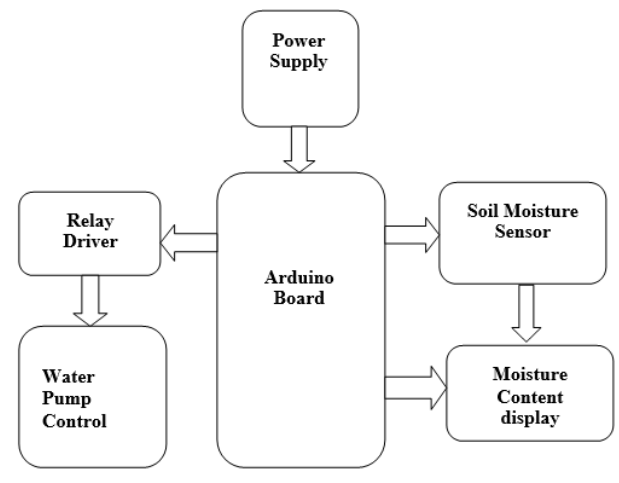

Fig. 2 Block diagram of the system

The above fig 2 shows Microcontroller based irrigation system proves to be a real time feedback control system which monitors and controls all the activities of drip irrigation system efficiently. The present proposal is a model to modernize the agriculture industries on a small scale with optimum expenditure. Using this system, one can save manpower, water to improve production and ultimately profit.

\section{RESULT}

Irrigation becomes easy, accurate and practical with the idea above shared and can be implemented in agricultural fields in future to promote agriculture to next level. The output from moisture sensor and level system plays major role in producing the output. 


\section{CONCLUSION}

The primary applications for this project are for farmers and gardeners who do not have enough time to water their crops/plants. It also covers those farmers who are wasteful of water during irrigation. The project can be extended to greenhouses where manual supervision is far and few in between. The principle can be extended to create fully automated gardens and farmlands. Combined with the principle of rain water harvesting, it could lead to huge water savings if applied in the right manner. In agricultural lands with severe shortage of rainfall, this model can be successfully applied to achieve great results with most types of soil.

\section{REFERENCES}

[1] Klute, A. (ed.), 1986: Methods of Soil Analysis, Part 1: Physical and Mineralogical Methods. American Society of Agronomy, Madison, Wisconsin, United States, $1188 \mathrm{pp}$.

[2] Knight, J.H., 1992: Sensitivity of time domain reflectometry measurements to lateral variations in soil water content. Water Resources Research, 28, pp. 2345-2352.

[3] Magagi, R.D., Kerr, Y.H., 1997. Retrieval of soil moisture and vegetation characteristics by use of ERS-1 wind scatterometer over arid and semi-arid areas. Journal of Hydrology 188-189, 361-384.

[4] Marthaler, H.P., W. Vogelsanger, F. Richard and J.P. Wierenga, 1983: A pressure transducer for field tensiometers. SoilScience Society of America Journal, 47, pp. 624-627.

[5] Attema, Evert, Pierre Bargellini, Peter Edwards, Guido Levrini, SveinLokas, Ludwig Moeller, BetlemRosich-Tell, et al 2007. Sentinel-1 - the radar mission for GMES operational land and sea services. ESA Bulletin 131: 10-17.

[6] Bircher, S., Skou, N., Jensen, K.H., Walker, J.P., \& Rasmussen, L. (2011). A soil moisture and temperature network forSMOS validation in Western Denmark. Hydrol. Earth Syst. Sci. Discuss., 8, 9961-10006. 